\title{
A case study on bright band transition from very light to heavy rain using simultaneous observations of collocated $\mathrm{X}$ - and Ka-band radars
}

\author{
Hari Krishna Devisetty, Ambuj K Jha*, Subrata K Das, Sachin M Deshpande, \\ U V Murali Krishna, Prasad M Kalekar and G Pandithurai \\ Radar and Satellite Meteorology Division, Indian Institute of Tropical Meteorology (IITM), \\ Dr Homi Bhabha Road, Pashan, Pune 411 008, India. \\ *Corresponding author.e-mail: ambuj.cat@tropmet.res.in
}

MS received 2 April 2018; revised 16 January 2019; accepted 1 February 2019; published online 14 May 2019

The observations of bright band carried out simultaneously with X-and Ka-band radars for the first time over the Indian region have been examined to reveal various contrasting characteristics of bright band at the two wavelengths. The study reports the bright band observations on September 12-13, 2015 at millimeter and centimeter wavelengths and brings out a comparative analysis of the bright band features (e.g., intensity, thickness, height, etc.) under three different rain conditions ranging from very light $(<0.1 \mathrm{~mm} / \mathrm{hr})$ to light $(0.1-3 \mathrm{~mm} / \mathrm{hr})$ to heavy $(3-5 \mathrm{~mm} / \mathrm{hr})$. It is seen that the bright band region at Ka-band is always narrower and situated at a higher altitude than at X-band frequency. Our analysis shows that at Ka-band frequency, the polarimetric fields like LDR can be utilized to detect and determine the bright band features using an appropriate selection of a threshold value of LDR, which is found to be $-22 \mathrm{~dB}$ in this study and could be associated reasonably with the top and bottom heights of the bright band. This study explores the potential of both radars, particularly the Ka-band radar for probing the bright band effect and estimating its features which would be helpful to improve the quantitative estimates of precipitation.

Keywords. Bright band; radar observations; precipitation; stratiform; radar polarimetry; cloud microphysics.

\section{Introduction}

The radar observed bright band (hereafter, BB) is a prominent feature of stratiform precipitation and appears as a shallow region of enhanced reflectivity just below the $0^{\circ} \mathrm{C}$ isotherm level in radar returns. This enhanced reflectivity results primarily due to rise in dielectric constant from the melting of snowflakes (0.19) to water (0.9) near the melting layer along with an increase in fall velocities of rain drops towards the end of the melting process (Battan 1973). Several observational studies have been conducted to understand the $\mathrm{BB}$ characteristics and explained the BB effect both qualitatively and quantitatively (Ryde 1946; Cunningham 1947; Austin and Bemis 1950; Marshall and Gunn 1952; Atlas et al. 1953; Wexler and Atlas 1956; Lhermitte and Atlas 1963; Fabry and Zawadzki 1995; Kowalewski and Peters 2010; Krishna et al. 2014).

The BB has been well-understood to result from Rayleigh dielectric scattering effect and it is only when the Rayleigh scattering approximations (when hydrometeors have diameters less than about one-tenth of the incident radiation wavelength) are fulfilled, a ubiquitous $\mathrm{BB}$ is seen in 
the radar images. This is the reason why the BB effect is distinctly detected at S-, L-, C- and X-bands (Smyth and Illingworth 1998; Matrosov et al. 2005) but not so prominently at Ka- and W-bands (Sassen et al. 2005). In these latter short wavelength bands, the hydrometeors are large enough to cause deviations from Rayleigh scattering conditions and as a result Mie scattering occurs (when hydrometeors have diameters larger than the wavelength of the incident radiation), which is noticed as attenuation in rain.

Numerous studies have been carried out to estimate the extent of BB using several techniques for accurate retrieval of radar based quantitative estimates of precipitation (Kitchen et al. 1994; Smyth and Illingworth 1998; Rico-Ramirez and Cluckie 2007; Zhang et al. 2008). A major portion of the BB observations so far has been carried out at a single wavelength, particularly at centimeter wavelengths. But as the BB physical features (e.g., intensity, thickness, peak height, top height, bottom height, etc.) may be interpreted differently depending on the radar resolution and wavelength (Hobbs et al. 1985; Matrosov 2010) there is a need to probe the BB effect simultaneously with different radars. The knowledge of $\mathrm{BB}$ features obtained at one wavelength can be applied to improve the quantitative estimates of precipitation for another wavelength radar (Rico-Ramirez et al. 2007). Hence, it is imperative to understand the $\mathrm{BB}$ effect through the perspective of different frequency radars and document the observations. In the past, several studies have investigated the BB phenomenon simultaneously at two wavelengths and demonstrated the distinct features observed at the two wavelengths (Hobbs et al. 1985; Thurai et al. 2001; Mardiana et al. 2004; Liao et al. 2009; Girolamo et al. 2012).

Over the Indian region, the BB studies are essential due to the fact that the stratiform precipitation, generally identified with the BB presence, accounts for $\sim 45 \%$ of the Indian summer monsoon rainfall (Pokhrel and Sikka 2012). Hence, an in-depth knowledge of the BB effect would enhance our understanding of the microphysical processes within the melting layer in monsoonal stratiform precipitation clouds. The BB studies over India have been conducted at single wavelength, mainly with centimeter wavelength radars, micro-rain radars and wind profilers (e.g., Biswas et al. 1962; Ramana Murty et al. 1965; Rao et al. 1999; Konwar et al. 2012; Jha et al. 2018). The present study is based on the idea that probing the $\mathrm{BB}$ region simultaneously with the cloud and precipitation radars under different rain conditions can bring out interesting aspects of BB features due to unique capabilities of both radars. This paper reports the $\mathrm{BB}$ events observed by the X-band (precipitation radar) and Ka-band (cloud radar) radars, having high spatial (temporal) resolutions of $50(1 \mathrm{~s})$ and $25 \mathrm{~m}(1 \mathrm{~s})$, respectively, installed at Mandhardev $\left(18.04^{\circ} \mathrm{N}, 73.86^{\circ} \mathrm{E}, \sim 1.3 \mathrm{~km} \mathrm{MSL}\right)$ during the Indian summer monsoon. The BB events have been obtained from simultaneous radar observations of September 12-13, 2015 under different rain conditions ranging from 0 to $5 \mathrm{~mm} / \mathrm{hr}$. These BB observations have been reported for the first time over the Indian region at two contrasting wavelengths, one (millimeter) considered limited for BB studies and the other (centimeter) considered suitable for BB studies. The analysis is limited to rain conditions up to $5 \mathrm{~mm} / \mathrm{hr}$ beyond which the attenuation becomes severe for cloud radar.

As the attenuation effect is considerable in higher rain conditions at Ka-band frequency (Lhermitte 1990; Aydin and Daisley 2002; Chandra et al. 2015), it becomes challenging to investigate the BB effect with a Ka-band radar as the $\mathrm{BB}$ signature is not so prominent in the reflectivity profiles and it becomes difficult to ascertain the BB features. Previous studies have shown that $\mathrm{BB}$ can be detected using the polarimetric fields like Linear Depolarization Ratio (LDR) (Caylor et al. 1990; Illingworth and Thompson 2011; Islam et al. 2012; Hall et al. 2015; Wolfensberger et al. 2016). It has been found by Hall et al. (2015) that LDR is the most suitable parameter for determining the full extent of BB. However, very few studies have estimated the BB features at Ka-band frequency using LDR (Tanelli et al. 2003; Chandrasekar and Khajonrat 2009). A cloud radar based study over Mandhardev by Jha et al. (2018) shows that the BB top height can be inferred using an appropriate selection of a threshold value of LDR. Here, it is found that LDR can be suitably used to extract both the BB top and bottom heights (and thus, its width). The BB signature is prominently present in LDR profiles even in rain events of $\sim 8 \mathrm{~mm} / \mathrm{hr}$ intensity as seen in this study. The BB features obtained at the two wavelengths have been compared and results are presented in the paper.

\section{Instrumentation and data}

The Indian Institute of Tropical Meteorology has deployed a magnetron based $200 \mathrm{~kW}$ X-band 


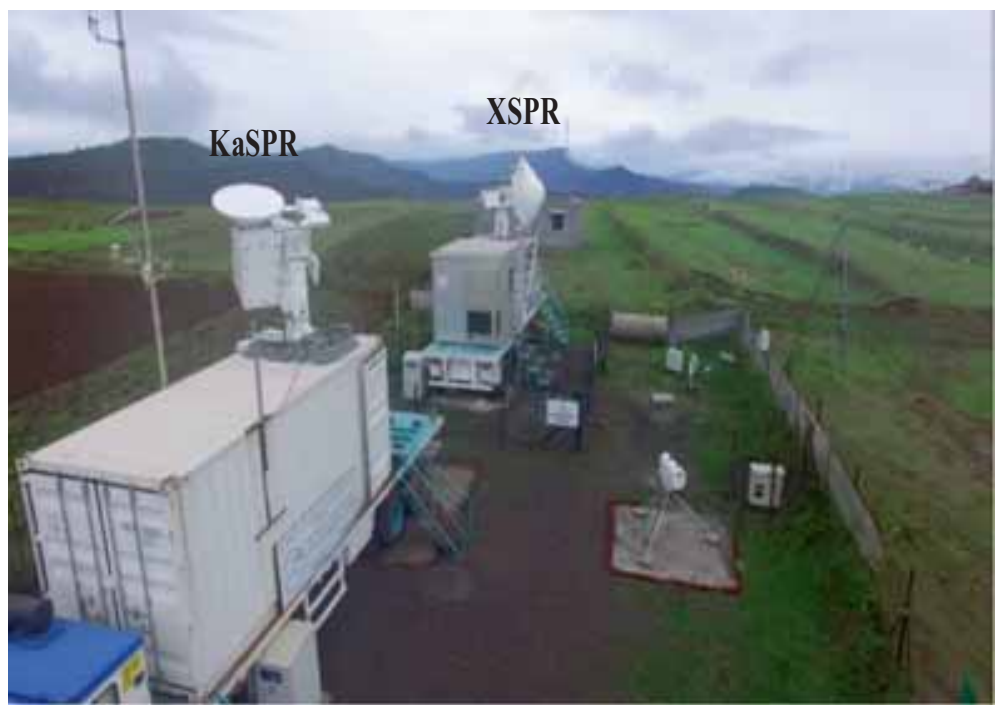

Figure 1. Radar site at Mandhardev $\left(18.04^{\circ} \mathrm{N}, 73.86^{\circ} \mathrm{E}, \sim 1.3 \mathrm{~km} \mathrm{MSL}\right)$ showing the deployment of KaSPR and XSPR.

Table 1. Technical specifications of X-band Scanning Polarimetric Radar (XSPR) and Ka-band Scanning Polarimetric Radar (KaSPR).

\begin{tabular}{lcc}
\hline Parameter & Value (X-band radar) & Value (Ka-band radar) \\
\hline Frequency $(\mathrm{GHz})$ & 9.535 & 35.29 \\
Wavelength $(\mathrm{cm})$ & 3.14 & 0.85 \\
Transmitter & Magnetron & Klystron (EIKA) \\
Peak power $(\mathrm{kW})$ & 200 & 2.2 \\
Pulse widths & $0.8-2 \mu \mathrm{s}$ & $50-13000 \mathrm{~ns}$ \\
Beam width & $0.97^{\circ}$ & $0.5^{\circ}$ \\
Antenna gain $(\mathrm{dB})$ & 44.3 & 49 \\
Antenna diameter $(\mathrm{m})$ & 2.4 & 1.2 \\
Cross-pol isolation $(\mathrm{dB})$ & -30 & -27 \\
Minimum detectable signal & $-25 \mathrm{dBZ}$ at $20 \mathrm{~km}$ & $-45 \mathrm{dBZ}$ at $5 \mathrm{~km}$ \\
\hline
\end{tabular}

Scanning Polarimetric Radar (XSPR) (9.535 GHz, $3.142 \mathrm{~cm})$ and a klystron based $2.2 \mathrm{~kW}$ Ka-band Scanning Polarimetric Radar (KaSPR) $(35.29 \mathrm{GHz}, 8.5 \mathrm{~mm})$ at Mandhardev $\left(18.04^{\circ} \mathrm{N}\right.$, $73.86^{\circ} \mathrm{E}$ and $\sim 1.3 \mathrm{~km}$ above MSL), a high altitude location in the Western Ghats region (figure 1). The scan strategy of KaSPR comprises three displays, namely, Plan Position Indicator (PPI), Range Height Indicator (RHI) and vertically pointing Height Time Indicator (HTI), all with a maximum range of $\sim 26 \mathrm{~km}$ while the XSPR's scans utilized here are Plan Position Indicator (PPI) and Range Height Indicator (RHI), all having a maximum range of $\sim 126 \mathrm{~km}$. The technical specifications of both the radars have been specified in table 1 . The surface precipitation intensity has been recorded using a collocated Joss-Waldvogel Disdrometer (JWD) with a sampling time of $30 \mathrm{sec}$.

\section{Methodology}

In the present work, the $\mathrm{BB}$ events have been selected from a variety of rain events that occurred on September 12-13, 2015. The rain events marked by $\mathrm{BB}$ presence have been grouped into three categories based on rain rates $(\mathrm{RR})$ recorded. For convenience, they have been grouped as very light $(<0.1 \mathrm{~mm} / \mathrm{hr}$, mean $\mathrm{RR} \sim 0.06 \mathrm{~mm} / \mathrm{hr})$, light $(0.1-3 \mathrm{~mm} / \mathrm{hr}$, mean $\mathrm{RR} \sim 2 \mathrm{~mm} / \mathrm{hr}$ ) and heavy (3-5 mm/hr, mean $\mathrm{RR} \sim 4.5 \mathrm{~mm} / \mathrm{hr})$ rain events. Each rain event is continuous in nature having duration of at least $10 \mathrm{~min}$. The $\mathrm{BB}$ event in a particular rain condition has been judged suitable only if it continuously occurs for more than 5 min during the rain event and has steady and consistent features (e.g., peak intensity, peak height, thickness) during the entire period. 


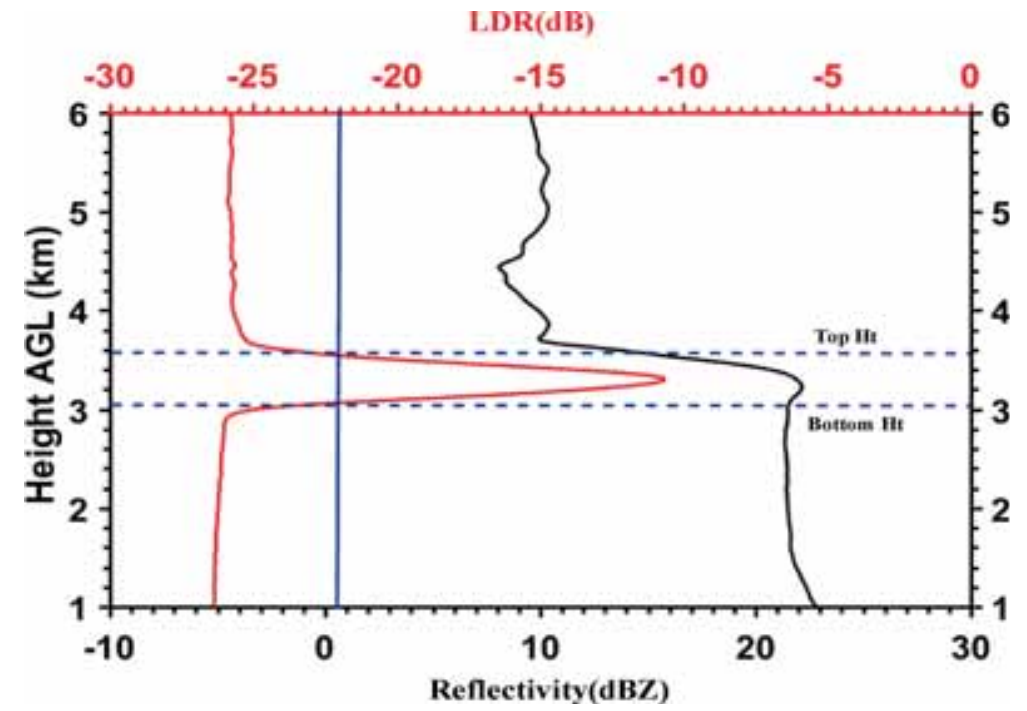

Figure 2. A representative image of KaSPR vertical profiles of reflectivity (solid black) and LDR (solid red) observed on September 12-13, 2015 where it is shown that the BB top and bottom heights (horizontal dashed lines) could be obtained from an $\mathrm{LDR}$ value of $-22 \mathrm{~dB}$ (indicated by blue vertical line).

For this study, near simultaneous RHI scans of XSPR and KaSPR having BB signatures have been examined. The vertical profiles of reflectivity (VPRs) and fall velocity (VPVs) under the 3 rain conditions have been investigated, which give us an insight into details of BB physical features when observed at two different wavelengths. The vertical profiles of reflectivity for XSPR have been extracted from PPI scans at $90^{\circ}$ elevation while those of KaSPR have been obtained from vertically pointing HTI scans. The BB features were obtained using suitable techniques discussed in the section below for a comparative analysis at two wavelengths.

\subsection{Determining the features of $B B$}

At X-band frequency, the BB features have been obtained from the vertical profiles of reflectivity. Each reflectivity profile is scanned and the peak of the profile is located, which provides the peak height and peak intensity of the BB (Klaassen 1988; Fabry and Zawadzki 1995). Thereafter, the altitude levels, above and below the maxima, where the slope of the profile is maximum are detected. These levels are defined as the top and bottom heights of the $\mathrm{BB}$ profile.

At Ka-band frequency, the $\mathrm{BB}$ signature is weakly noticeable under heavy rain conditions while it is prominently observed in very light rain events. Therefore, in very light rain events, the $\mathrm{BB}$ features have been extracted similar to that of VPRs of XSPR whereas under higher rain conditions, the $\mathrm{BB}$ features were obtained using characteristic polarimetric signature of LDR. An LDR value of $-22 \mathrm{~dB}$ has been found to be associated with the top height of $\mathrm{BB}$ as observed in a cloud radar based BB case study by Jha et al. (2018) over Mandhardev. Here, after a careful analysis of the entire dataset, it has been observed that $-22 \mathrm{~dB}$ could be the most appropriate LDR value to be associated with both the top and bottom heights of BB for this study (figure 2). After this, the peak height is determined at which reflectivity attains a maximum between the top and bottom height levels.

The mean values of $\mathrm{BB}$ features under the 3 rain conditions so obtained are tabulated appropriately in table 2. Nearly 500 profiles each of reflectivity and velocity for each radar and additional $\sim 500$ LDR profiles of KaSPR have been analyzed for obtaining the average values shown in table 2 .

\section{Results and discussion}

Figure 3 shows near simultaneous RHI scans (with BB signatures) of XSPR and KaSPR for stratiform rain observed on September 12-13, 2015. The rain rate for top panel is 11.7 and $0.12 \mathrm{~mm} / \mathrm{hr}$ for bottom panel at radar location, as measured from JWD and it is assumed that the rain intensity is nearly uniform for the entire range of RHI scan. At $11.7 \mathrm{~mm} / \mathrm{hr}$ rainfall, it is seen that 
Table 2. Mean BB features obtained.

\begin{tabular}{lccc}
\hline & $\begin{array}{c}\mathrm{RR}<0.1 \mathrm{~mm} / \mathrm{hr} \\
(\text { Mean RR is } 0.06 \mathrm{~mm} / \mathrm{hr})\end{array}$ & $\begin{array}{c}\mathrm{RR} \text { is } 0.1-3 \mathrm{~mm} / \mathrm{hr} \\
(\text { Mean RR is } \sim 2 \mathrm{~mm} / \mathrm{hr})\end{array}$ & $\begin{array}{c}\mathrm{RR} \text { is }-5 \mathrm{~mm} / \mathrm{hr} \\
(\mathrm{Mean} \mathrm{RR} \text { is } \sim 4.5 \mathrm{~mm} / \mathrm{hr})\end{array}$ \\
\hline BB peak height $(\mathrm{km}) \mathrm{X}(\mathrm{Ka})$ & $3.325(3.591)$ & $3.075(3.216)$ & $3.025(3.116)$ \\
BB peak intensity (dBZ) X (Ka) & $21(19.81)$ & $34.77(22.16)$ & $37.09(17.94)$ \\
BB top height $(\mathrm{km}) \mathrm{X}(\mathrm{Ka})$ & $3.675(3.780)$ & $3.575(3.541)$ & $3.625(3.61)$ \\
BB bottom height $(\mathrm{km}) \mathrm{X}(\mathrm{Ka})$ & $2.975(3.390)$ & $2.625(3.066)$ & $2.575(2.96)$ \\
BB thickness $(\mathrm{m}) \mathrm{X}(\mathrm{Ka})$ & $700(390)$ & $950(475)$ & $1050(650)$ \\
KaSPR LDR peak $(\mathrm{dB})$ & -13.46 & -10.67 & -10.37 \\
KaSPR LDR peak ht $(\mathrm{km})$ & 3.516 & 3.291 & 3.291 \\
\hline
\end{tabular}

(a)

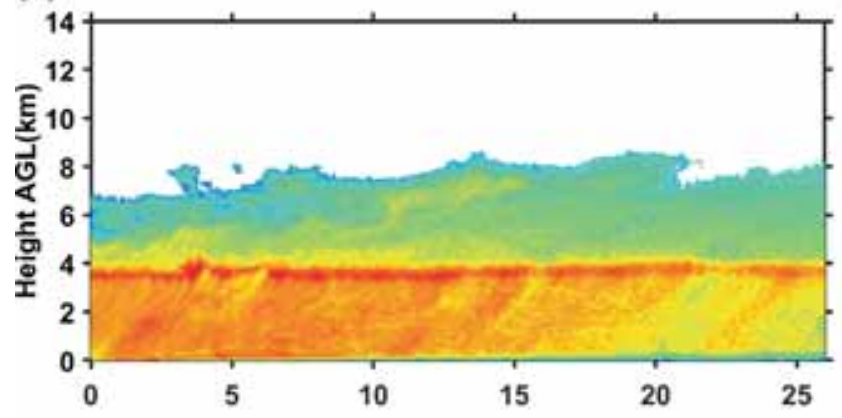

(c)

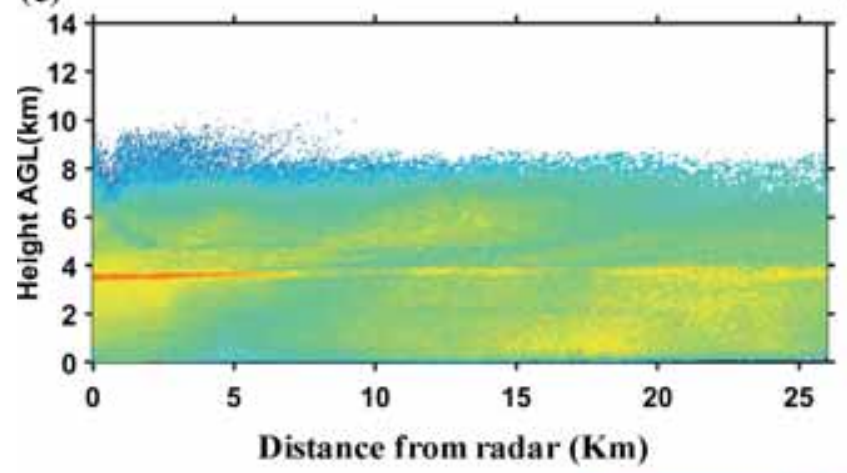

(b)

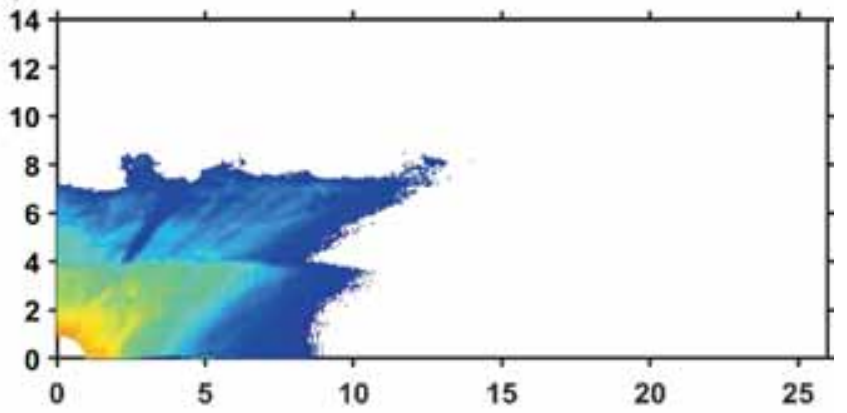

(d)

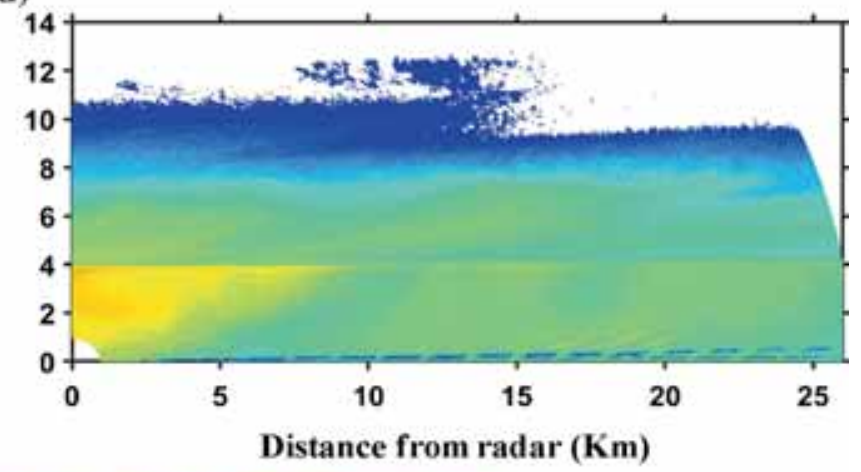

Distance from radar $(\mathrm{Km})$

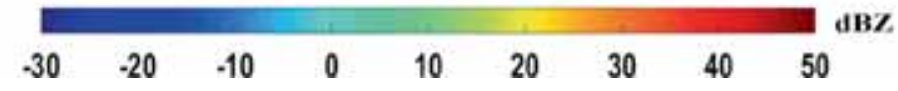

Figure 3. RHI reflectivity scans observed on September 12-13, 2015 of XSPR (left panel) and KaSPR (right panel) during surface rainfall rate (at radar location) of (a), (b) $11.7 \mathrm{~mm} / \mathrm{hr}$ and (c), (d) $0.12 \mathrm{~mm} / \mathrm{hr}$.

the XSPR scans show a prominent BB which is indiscernible in KaSPR scans (figure $3 \mathrm{a}$ and $\mathrm{b}$ ). This is mainly due to heavy attenuation faced by the cloud radar, which is so severe in heavy rain that the radar's signal suffers extinction as seen in figure 3(b). However, at lower rain rates of $0.12 \mathrm{~mm} / \mathrm{hr}$, the $\mathrm{BB}$ signature is noticeable in both KaSPR and XSPR scan images, though more prominently in XSPR image (figure 3c and d). Nevertheless, the cloud radar is advantageous at $0.12 \mathrm{~mm} / \mathrm{hr}$ for the reason that it detects the weak reflectivity values associated with the cloud tops more precisely than the precipitation radar (figure 3d).
Although the BB may appear fuzzy in KaSPR reflectivity pictures at higher rain rates, it is distinctively visible in the LDR profiles in all rain events up to $5 \mathrm{~mm} / \mathrm{hr}$ and even beyond (figures 4 and 6).

\subsection{Mean profiles of reflectivity}

The mean VPRs of KaSPR and XSPR have been obtained for the three rainfall groups (figure $4 \mathrm{a}-\mathrm{c}$ ). Firstly, it can be observed that the BB signature is much more pronounced in XSPR profiles which is also seen with the previously discussed RHI scan images. Secondly, it is seen that as the 

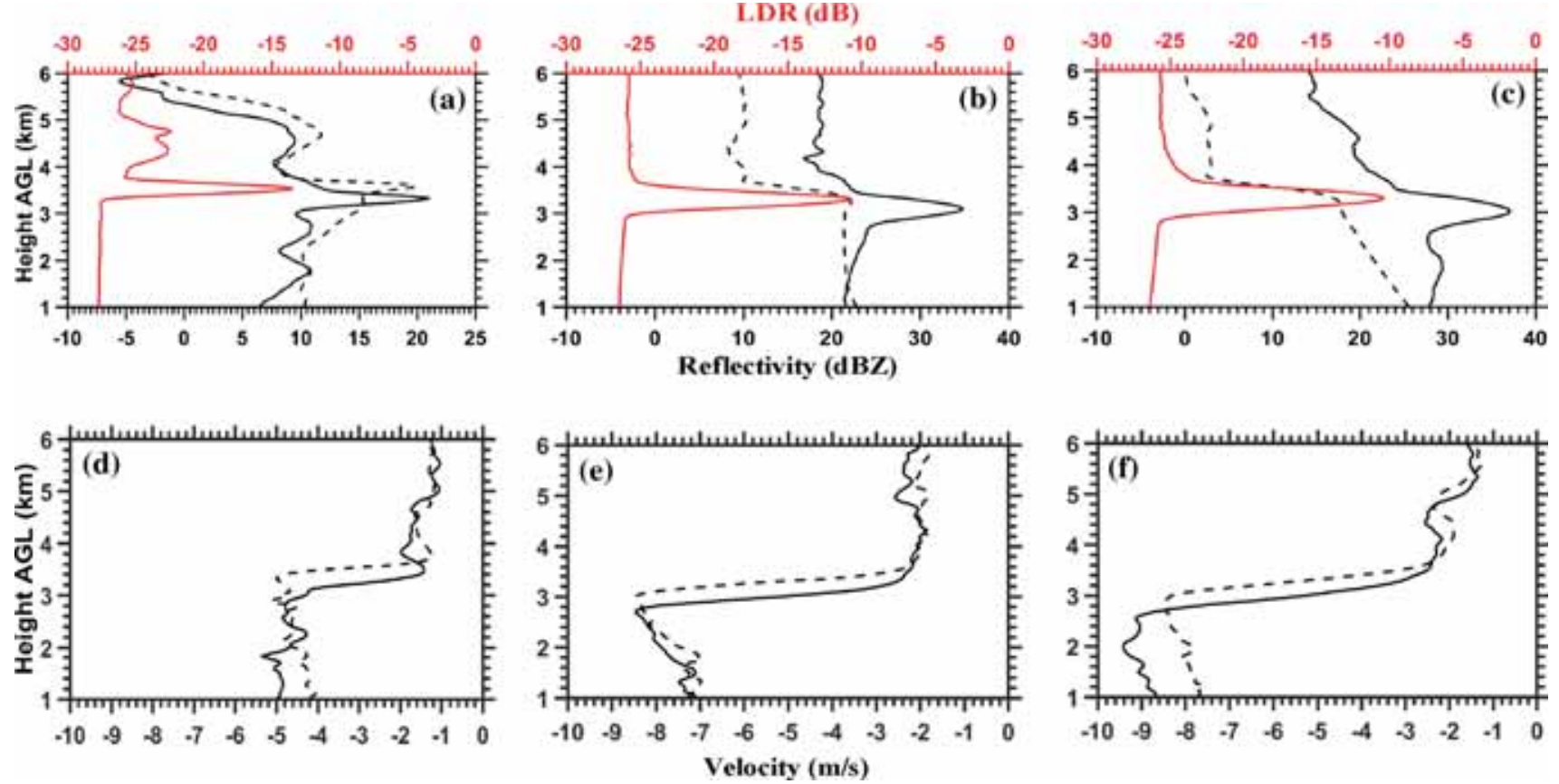

Figure 4. The top panel shows the vertical profiles of reflectivity of KaSPR (dashed black), of XSPR (solid black) and vertical profiles of LDR (solid red) while the bottom panel shows the vertical profiles of fall velocity of KaSPR (dashed black) and of XSPR (solid black) in (a), (d) very light rain $(<0.1 \mathrm{~mm} / \mathrm{hr}, \mathrm{mean} \mathrm{RR} \sim 0.06 \mathrm{~mm} / \mathrm{hr}),(\mathbf{b}),(\mathbf{e})$ light rain $(0.1-3 \mathrm{~mm} / \mathrm{hr}$, mean $\mathrm{RR} \sim 2 \mathrm{~mm} / \mathrm{hr}$ ) and (c), (f) heavy rain event $(3-5 \mathrm{~mm} / \mathrm{hr}, \mathrm{mean} \mathrm{RR} \sim 4.5 \mathrm{~mm} / \mathrm{hr}$ ).

precipitation intensity increases from very light to heavy rain, the $\mathrm{BB}$ peak intensity (except for KaSPR in heavy rain event due to attenuation) and thickness get enhanced while the peak height falls to lower altitude levels (see figure $4 \mathrm{a}-\mathrm{c}$ and table 2). The descent of BB peak height to lower altitudes can be clearly seen in the scatter plot in figure 5. The BB peak heights obtained at both frequencies are seen to be nicely clustered together in all rain events. The gap between the clusters is large when there is a transition from very light to light rain event. This is because of the substantial descent of $\mathrm{BB}$ to lower altitudes during very light $(<0.1 \mathrm{~mm} / \mathrm{hr})$ to light rain $(0.1-3 \mathrm{~mm} / \mathrm{hr})$ transitions than when rain intensity shifts from light rain to heavy rain group $(3-5 \mathrm{~mm} / \mathrm{hr})$.

Thirdly, the BB top heights first decrease from very light to light rain event and then increase in heavy rain event whereas the BB bottom heights show a constant decreasing trend with increase in rain rate. Further, it is noted that the BB peaks in KaSPR's VPRs are located at a higher level (266, 141 and $91 \mathrm{~m}$ higher in very light, light and heavy rain, respectively) than that of XSPR (table 2). There is no enhancement in reflectivity in KaSPR's VPR corresponding to the BB peak level in XSPR's VPR in all rain conditions (figure $4 \mathrm{a}-\mathrm{c}$ ). This is due to the presence of larger melting snowflakes at the BB peak level observed in XSPR's VPR, which cause the Ka-band signal to attenuate considerably and hence, the reflectivity fails to rise at that level. It is only when the Mie scattering effect drops and Rayleigh conditions are fulfilled at higher altitude levels where comparatively smaller sized particles are present (Brown 1964), the KaSPR's VPR attains a maximum and the $\mathrm{BB}$ peak appears. It is also noticeable that under very light rain conditions of $\sim 0.06 \mathrm{~mm} / \mathrm{hr}$, the VPR of KaSPR is leading slightly (figure 4a), whereas under higher rain conditions the VPR of KaSPR is lagging behind that of XSPR (figure 4b and c). This indicates that under very light rain conditions when attenuation effect is negligible, smaller particles in the radar sampling volume are also accounted robustly by KaSPR which otherwise go undetected by XSPR, thereby producing higher backscattered returns and a leading VPR.

\subsection{Mean profiles of velocity and $L D R$}

The mean VPVs of both radars show similarity for the most part (figure $4 \mathrm{~d}-\mathrm{f}$ ). Within the BB region, the KaSPR's VPVs are elevated with respect to XSPR's VPVs, which may be due to the fact that the Ka-band radar detects the $\mathrm{BB}$ region higher than X-band radar which is clearly seen in the VPRs. 


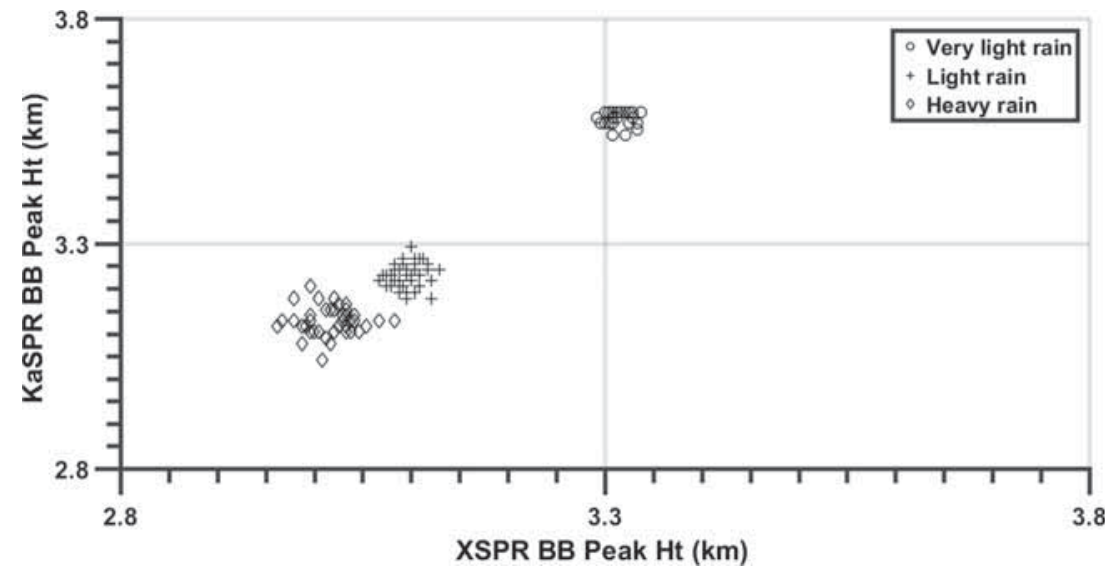

Figure 5. Scatter plot of BB peak heights observed by KaSPR and XSPR. The heights are above ground level.
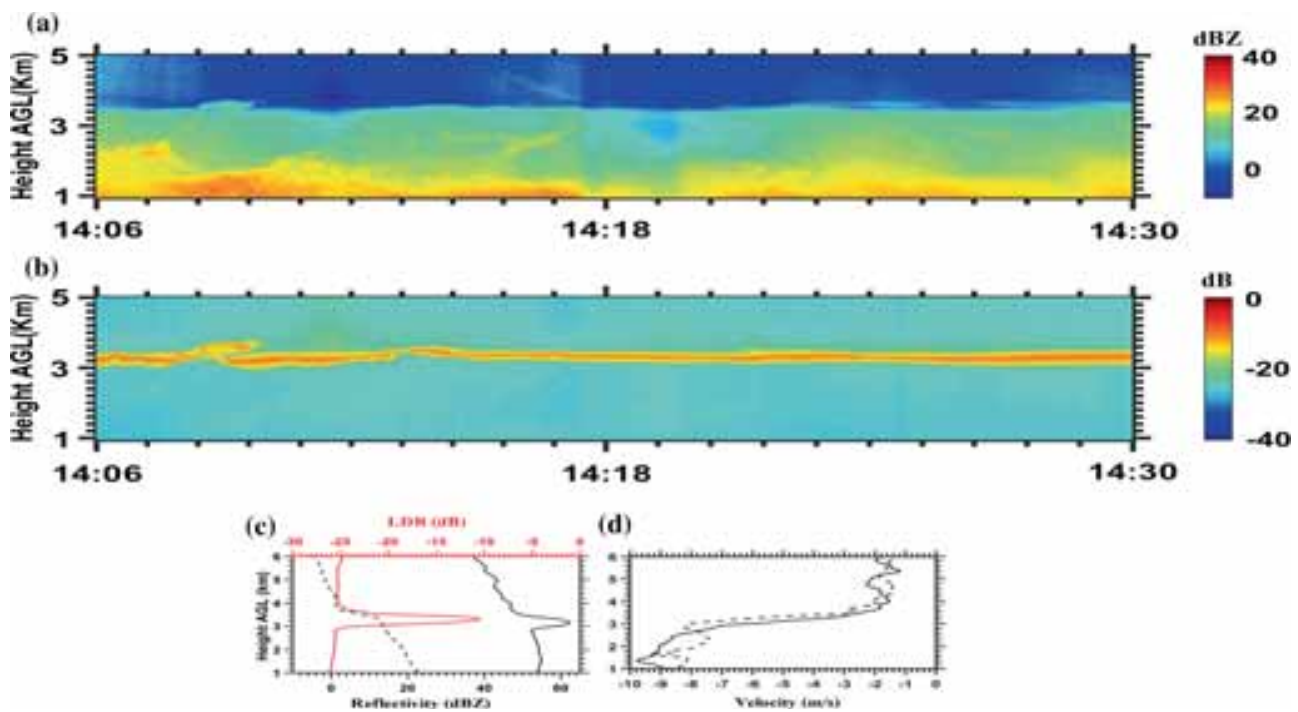

Figure 6. Radar observations of September 12, 2015 showing (a) KaSPR reflectivity image, (b) KaSPR LDR image (time in UTC), (c) mean vertical profile of reflectivity of KaSPR (dashed black), of XSPR (solid black) and mean vertical profile of LDR (solid red), (d) mean vertical profiles of velocity of KaSPR (dashed black) and XSPR (solid black) in a rainfall event of $\sim 8 \mathrm{~mm} / \mathrm{hr}$ intensity.

In addition to the VPRs and VPVs, the vertical profiles of KaSPR's LDR are also presented, which show a well defined $\mathrm{BB}$ presence under all rain conditions. Beyond the three rain events, the $\mathrm{BB}$ presence is confirmed in LDR images even at $\sim 8 \mathrm{~mm} / \mathrm{hr}$, which shows the potential of LDR (figure 6). In this case study, it is seen that $-22 \mathrm{~dB}$ LDR value could be associated appropriately with the $\mathrm{BB}$ top and bottom heights in all three rain events. However, in very light rain event the attenuation effect is minor and therefore, the $\mathrm{BB}$ top and bottom heights have been obtained from the reflectivity and the LDR profile as well and it is seen that there is a good agreement in values obtained from both. For higher rain events, the LDR profiles have been utilized to extract the top and bottom levels of $\mathrm{BB}$ (see values in table 2), which nearly encompass the $\mathrm{BB}$ region of KaSPR as seen in figure 2. However, with increasing rain rates, it gets relatively tougher to quantify the BB thickness even with LDR profiles. For example, at 8 $\mathrm{mm} / \mathrm{hr}$ rain rate, the $\mathrm{BB}$ can be located correctly using LDR but its thickness should be estimated carefully from LDR profiles. This is the reason why we have restricted our analysis to $5 \mathrm{~mm} / \mathrm{hr}$. The LDR peak values and corresponding altitude levels increase and decrease, respectively, with rise in precipitation intensity from very light to heavy rain (see table 2). Also, it is observed that the $\mathrm{BB}$ thickness estimated by $\mathrm{X}$-band radar is wider than the LDR detected BB thickness (at Ka-band). It is mainly due to the conventional gradient method adopted for X-band radar and 
its lower spatial resolution, which gives broader BB while the LDR method for Ka-band radar is conservative. As the Ka-band radar sees a narrower $\mathrm{BB}$ than the $\mathrm{X}$-band radar due to attenuation effect, the methods adopted are believed to be suitable. Lastly, it is noted that the LDR peak of Ka-band radar is observed at a higher altitude level than the reflectivity peak of X-band radar in all rain events except in very light rain event $(<0.1 \mathrm{~mm} / \mathrm{hr})$. As LDR peak is associated with a spherical, canted particles that are wetted, it may indicate that there is an increased fluttering or spinning of mixed-phase particles (Ikeda et al. 2005) above the altitude level of reflectivity peak at X-band.

\section{Summary and conclusion}

The study is a first of its kind attempt conducted over the Indian region to bring out a comparative analysis of BB features at millimeter and centimeter wavelengths under rain conditions ranging from very light to light to heavy. The near simultaneous RHI observations at X- and Ka-band frequencies show that the Ka-band radar observations are comparable to that of X-band in light rain events of $\sim 0.12 \mathrm{~mm} / \mathrm{hr}$ intensity, whereas in very heavy rain of $\sim 11.7 \mathrm{~mm} / \mathrm{hr}$ intensity, Ka-band radar may not be useful enough for BB study. It is noted that under light rain conditions of $\sim 0.12 \mathrm{~mm} / \mathrm{hr}$, the high sensitivity of cloud radar is helpful in more precise cloud top detection, which may get underestimated by the precipitation radar. Further, the mean VPRs show that the BB has a more well-pronounced structure in XSPR reflectivity images than that of KaSPR, which can be attributed to the attenuation and Mie scattering effect at Ka-band. The BB peak intensity (except for KaSPR in heavy rain event) and thickness increase while the peak height falls with an increase in precipitation intensity from very light to heavy rain, which has been observed and established by earlier studies as well. The study reveals many important features of $\mathrm{BB}$ when viewed with different radars. The $\mathrm{BB}$ region detected at Ka-band is always narrower and situated at a higher altitude than at X-band. The KaSPR reflectivity profiles peak at a higher level (266, 141 and $91 \mathrm{~m}$ higher in very light, light and heavy rain, respectively) than XSPR reflectivity profiles under all rain conditions. This may be due to the reason that Ka-band radar could detect $\mathrm{BB}$ only at higher altitude levels when Mie scattering effect reduces and Rayleigh conditions are fulfilled due to the presence of smaller sized particles. Furthermore, in very light rain conditions of $\sim 0.06 \mathrm{~mm} / \mathrm{hr}$, the reflectivity profile of Ka-band radar is of leading nature whereas lagging in higher rain conditions. This shows that the Ka-band radar can be very useful in complementing the observations of a precipitation radar but only during light rain conditions when it does not suffer heavy attenuation.

Our analysis shows that the BB and its features can be identified with the help of polarimetric fields like LDR at Ka-band frequency even under heavy rain conditions up to $5 \mathrm{~mm} / \mathrm{hr}$. Though several studies have utilized LDR to determine the extent of BB, but not many have estimated the BB features using LDR at Ka-band frequency. A simple technique is proposed to infer the BB top and bottom heights (and thus, its width also) using an appropriate selection of a threshold value of LDR (here, we used $-22 \mathrm{~dB}$ ) under reported rain conditions. Apart from the rain events analyzed here, another higher rain event of $\sim 8 \mathrm{~mm} / \mathrm{hr}$ intensity is considered where the $\mathrm{BB}$ is seen clearly in LDR images which shows the potential of the LDR to explore the BB (figure 6).

This comparative study explores the BB effect and unravels striking features when viewed at millimeter and centimeter wavelengths. The knowledge of $\mathrm{BB}$ features at one wavelength can be applied to improve the quantitative estimates of precipitation for another wavelength radar. The potential of both radars is explored, particularly the Ka-band radar for probing the BB effect under various rain conditions. The study can be further extended to include regions above and below the BB using both radars for a wholesome understanding of the processes occurring in the stratiform cloud system which would be helpful in deriving the BB-surface rain relation at both wavelengths.

\section{Acknowledgements}

IITM is an autonomous organization and fully funded by the Ministry of Earth Science, Government of India. Authors are grateful to the Director, IITM, for the kind support and constant encouragement. We thank and acknowledge Dr. Madhu Chandra R Kalapureddy who encouraged this study and provided useful suggestions in the 
initial stage which greatly helped in framing the outline of the study. Excellent help/support and involvement of all those right from the inception of IITM's radar program is thankfully acknowledged.

\section{References}

Atlas D, Kerker M and Hitschfeld W 1953 Scattering and attenuation by non-spherical atmospheric particles; $J$. Atmos. Terr. Phys. 3 108-119.

Austin P M and Bemis A C 1950 A quantitative study of the 'bright band' in radar precipitation echoes; J. Meteorol., https://doi.org/10.1175/1520-0469(1950)007,0145: AQSOTB.2.0.CO;2.

Aydin K and Daisley S E A 2002 Relationships between rainfall rate and $35 \mathrm{GHz}$ attenuation and differential attenuation: Modeling the effects of raindrop size distribution, canting, and oscillation; IEEE T. Geosci. Remote $402343-2351$.

Biswas K R, Ramana Murty B V and Roy A K 1962 Freezing rain at Delhi and associated melting band characteristics; Indian J. Meteorol. Geophys. 13 137-142.

Battan L J 1973 Radar observations of the atmosphere; The University of Chicago Press, 279p.

Caylor I J, Goddard J W F, Hopper S E and Illingworth A J 1990 Bright band errors in radar estimates of rainfall: Identification and correction using polarization diversity; In: Weather Radar Networking (eds) Collier C G and Chapuis M, COST project 73, EUR 12414 EN-FR document EUCO-COST 73/52/90, pp. 294-303.

Chandra A, Zhang C, Kollias P, Matrosov S and Szyrmer W 2015 Automated rain rate estimates using the Ka-band ARM zenith radar (KAZR); Atmos. Meas. Tech. 8 36853699 .

Chandrasekar V and D Khajonrat 2009 Simulation of spaceborne radar observations of precipitation at $\mathrm{Ku}$ and $\mathrm{Ka}$ band; 34th Conference on Radar Meteorology, Williamsburg, VA.

Cunningham R M 1947 A different explanation of the "bright line"; J. Meteorol. 4163.

Edward N Brown 1964 Observations of the micro-structure of a radar bright band and associated shower; Tellus 16(4) 518-522, https://doi.org/10.3402/tellusa.v16i4.8987.

Fabry F and Zawadzki I 1995 Long-term radar observations of the melting layer of precipitation and their interpretation; J. Atmos. Sci. 52 838-851, https://doi.org/10.1175/ 1520-0469(1995)052,0838:LTROOT.2.0.CO;2.

Girolamo P D, Summa D, Cacciani M, Norton E G, Peters G and Dufournet Y 2012 Lidar and radar measurements of the melting layer: Observations of dark and bright band phenomena; Atmos. Chem. Phys. 12 4143-4157.

Hall W, Rico-Ramirez M A and Kramer S 2015 Classification and correction of the bright band using an operational Cband polarimetric radar; J. Hydrol. 531 248-258, https:// doi.org/10.1016/j.jhydrol.2015.06.011.

Hobbs P V, Funk N T, Weiss R R, Locatelli J D, and Biswas K R 1985 Evaluation of a $35 \mathrm{GHz}$ radar for cloud physics research; J. Atmos. Oceanic Tech. 2 35-48, https://doi.org/10.1175/1520-0426(1985)002, 0035:EOAGRF.2.0.CO;2.
Ikeda K, Brandes E A and Rasmussen R M 2005 Polarimetric radar observations of multiple freezing levels; J. Atmos. Sci. 62 3624-3636.

Illingworth A and Thompson R 2011 Radar bright band correction using the linear depolarisation ratio; Weather Radar and Hydrology, Proceedings of a Symposium held in Exeter, UK, April 2011.

Islam T, Rico-Ramirez M A, Han D, Bray M and Srivastava P K 2012 Fuzzy logic based melting layer recognition from $3 \mathrm{GHz}$ dual polarization radar: appraisal with NWP model and radio sounding observations; Theor. Appl. Climatol. 112 317-338, https://doi.org/10.1007/ s00704-012-0721-z.

Jha A K, Kalapureddy M C R, Devisetty H K, Deshpande S M and Pandithurai G 2018 A case study on large-scale dynamical influence on bright band during the Indian summer monsoon; Meteorol. Atmos. Phys., https://doi. org/10.1007/s00703-018-0583-8.

Kitchen M, Brown R and Davies A G 1994 Real-time correction of weather radar data for the effects of bright band, range and orographic growth in widespread precipitation; Quart. J. Roy. Meteorol. Soc. 120 1231-1254.

Klaassen W 1988 Radar observations and simulation of the melting layer of precipitation; J. Atmos. Sci. 45 37413753.

Konwar M, Maheskumar R S, Das S K and Morwal S B 2012 Nature of light rain during presence and absence of bright band; J. Earth Syst. Sci. 121 947-961.

Kowalewski S and Peters G 2010 Analysis of Z-R relations based on LDR signatures within the melting layer; $J$. Atmos. Oceanic Tech. 27 155-156.

Krishna U V M, Reddy K K, Mastanaiah R, Shirooka R and Pan C J 2014 Observational study on melting layer characteristics over Palau in Pacific Ocean; J. Atmos. Sol. Terr. Phys. 121 132-140.

Lhermitte R 1990 Attenuation and scattering of millimeter wavelength radiation by cloud and precipitation; $J$. Atmos. Ocean Tech. 7 464-479.

Lhermitte R M and Atlas D 1963 Doppler fall speed and particle growth in the stratiform precipitation; 10th Radar Meteorology Conference, Washington DC, pp. 297-302.

Liao L, Meneghini R, Tian L and Heymsfield G M 2009 Measurements and simulations of nadir-viewing radar returns from the melting layer at $\mathrm{X}$ and $\mathrm{W}$ bands; $J$. Appl. Meteor. Climatol. 48 2215-2226, https://doi.org/ 10.1175/2009JAMC2033.1.

Mardiana R, Iguchi T and Takahashi N 2004 A dualfrequency rain profiling method without the use of a surface reference technique; IEEE Trans. Geosci. Remote Sens. 42 2214-2225.

Marshall J S and Gunn K L 1952 Measurement of snow parameters by radar; J. Meteor. 9 322-327, https://doi.org/10.1175/15200469(1952)009<0322:MOSP $\mathrm{BR}>2.0 . \mathrm{CO} ; 2$.

Matrosov S Y, Kingsmill D E, Martner B E and Ralph F M 2005 The utility of X-band polarimetric radar for quantitative estimates of rainfall parameters; J. Hydrometeorol. $6248-262$.

Matrosov S Y 2010 Synergetic use of millimeter- and centimeter-wavelength radars for retrievals of cloud and rainfall parameters; Atmos. Chem. Phys. 10 3321-3331, https://doi.org/10.5194/acp-10-3321-2010. 
Pokhrel S and Sikka D R 2012 Variability of the TRMM-PR total and convective and stratiform rain fractions over the Indian region during the summer monsoon; Clim. Dyn., https://doi.org/10.1007/s00382-012-1502-1.

Ramana Murty B V, Roy A K and Biswas K R 1965 Radar echo intensities below bright band; J. Atmos. Sci. 22 9194.

Rao T N, Narayana Rao D and Raghavan S 1999 Tropical precipitating systems observed with Indian MST radar; Radio Sci. 34 1125-1139.

Rico-Ramirez M A and Cluckie I D 2007 Bright-band detection from radar vertical reflectivity profiles; Int. J. Remote Sens. 28 4013-4025, https://doi.org/10.1080/ 01431160601047797.

Rico-Ramirez M A, Cluckie I D, Shepherd G and Pallot A 2007 A high resolution radar experiment on the island of Jersey; Meteorol. Appl. 14 117-129.

Ryde J W 1946 The attenuation and radar echoes produced at centimeter wavelengths by various meteorological phenomena; Meteorological Factors in Radio Wave Propagation, The Physical Society, pp. 169188.

Sassen K, Campbell J R, Zhu J, Kollias P, Shupe M and Williams C 2005 Lidar and triple-wavelength Doppler radar measurements of the melting layer: A revised model for dark and bright band phenomena; J. Appl. Meteor. 44 301-312.

Smyth T J and Illingworth A J 1998 Radar estimates of rainfall rates at the ground in bright band and non-bright band events; Quart. J. Roy. Meteorol. Soc. 124 24172434.

Tanelli S, Meagher J, Durden S and Im E 2003 Multiparametric airborne radar observations of the melting layer during the Wakasa Bay experiment; In: Proceedings of 31st International Conference on Radar Meteorology, pp. 33-34.

Thurai M, Kumagai H, Kozu T and Awaka J 2001 Effects of incorporating a bright band model in a downward-looking radar rainfall retrieval algorithm; J. Atmos. Oceanic Tech. $1820-25$.

Wexler R and Atlas D 1956 Factors influencing radar-echo intensities in the melting layer; Quart. J. Roy. Meteorol. Soc., https://doi.org/10.1002/qJ497-08235-312.

Wolfensberger D, Scipion D and Berne A 2016 Detection and characterization of the melting layer based on polarimetric radar scans; Quart. J. Roy. Meteorol. Soc. 142 108-124, https://doi.org/10.1002/qj.2672.

Zhang J, Langston C and Howard K 2008 Bright band identification based on vertical profiles of reflectivity from the WSR-88D; J. Atmos. Oceanic Tech. 25 1859-1872. 